\title{
Oxygen Plasma/Bismuth Modified Inkjet Printed Graphene Electrode for the Sensitive Simultaneous Detection of Lead and Cadmium
}

\author{
Léopoldine Sonfack Guenang1,2, Prachi Gupta ${ }^{3}$, Victor Costa Basseto ${ }^{3}$, Milica Jovic ${ }^{3}$, \\ Ervice Ymélé1, Andreas Lesch ${ }^{3}$, Hubert Girault ${ }^{3}$, Ignas Kenfack Tonlé1 \\ ${ }^{1}$ Electrochemistry and Chemistry of Materials, Department of Chemistry, University of Dschang, Dschang, Cameroon \\ ${ }^{2}$ Inorganic Chemistry Laboratory, Department of Chemistry, University of Buea, Buea, Cameroon \\ ${ }^{3}$ Laboratoired' Electrochimie Physique et Analytique (LEPA), Ecole Polytechnique Fédérale de Lausanne, Lausanne, Switzerland \\ Email: itonle@yahoo.com
}

How to cite this paper: Guenang, L.S., Gupta, P., Basseto, V.C., Jovic, M., Ymélé, E., Lesch, A., Girault, H. and Tonlé, I.K. (2020) Oxygen Plasma/Bismuth Modified Inkjet Printed Graphene Electrode for the Sensitive Simultaneous Detection of Lead and Cadmium. American Journal of Analytical Chemistry, 11, 1-14.

https://doi.org/10.4236/ajac.2020.111001

Received: October 22, 2019

Accepted: January 11, 2020

Published: January 14, 2020

Copyright $\odot 2020$ by author(s) and Scientific Research Publishing Inc. This work is licensed under the Creative Commons Attribution International License (CC BY 4.0).

http://creativecommons.org/licenses/by/4.0/

\section{(c) (i) Open Access}

\begin{abstract}
In this work, a simple procedure for the preparation of an inkjet printed disposable graphene electrode is reported. Commercial graphene ink was printed on a kapton substrate and the resulting electrode was 30 min treated by oxygen plasma, then modified by a bismuth salt. The as prepared electrode was characterized by Raman spectroscopy, X-ray photoelectron spectroscopy (XPS), laser scanning microscopy (LSM) and scanning electron microscopy (SEM) coupled to energy-dispersive X-ray spectroscopy (EDX). The sensing properties of the characterized electrodes were then investigated using cyclic voltammetry and Electrochemical Impedance Spectroscopy (EIS). Afterwards, these electrodes were exploited in a comparative way for the electroanalysis of Cadmium(II) and Lead(II) ions. An increase in the electrode sensitivity due to its modification and to the presence of bismuth was observed. Some preliminary experiments based on stripping square wave voltammetry highlighted the interest of using the proposed disposable inkjet printed electrodes for the electrochemical detection of heavy metals in tap water.
\end{abstract}

\section{Keywords}

Inkjet Printing Technology, Disposable Printed Graphene Electrode, Heavy Metals, Stripping Voltammetry

\section{Introduction}

Environmental pollution constitutes a daily and emergent concern for both the developing and developed countries due to industrialization, economic devel- 
opment, and high population growth. In fact, various toxic organic and inorganic substances are frequently introduced into the environment from either natural or anthropogenic sources [1] [2]. The most common inorganic environmental pollutants are heavy metals, defined to be metallic elements with a density greater than $5 \mathrm{~g} \cdot \mathrm{cm}^{-3}$ [2] [3], and atomic numbers greater than 20 [4]. Heavy metals also include metalloids, such as arsenic, that are able to bring toxicity at a low level of exposure [5]. Lead and cadmium are among the ten chemicals identified by the WHO as major public health concern [6]. They are released into the environment from painting activities, and from the manufacturing and recycling of batteries [7] [8]. Lead is classified as a probable human carcinogen by the International Agency for Research on Cancer (IARC) [8], while cadmium has also been identified as a human carcinogen [9]. The WHO set permissible limits of lead and cadmium concentration in drinking water as $0.01 \mathrm{mg} \cdot \mathrm{L}^{-1}$ and $0.003 \mathrm{mg} \cdot \mathrm{L}^{-1}$, respectively [9].

To monitor or quantify these toxic heavy metals, several methods are commonly used, that include atomic absorption spectrometry (AAS), inductively coupled plasma mass spectrometry (ICP-MS) and anodic stripping voltammetry (ASV). The spectroscopic methods (AAS and ICP-MS) require a well-equipped laboratory infrastructure, tedious sample preparation, skilled manpower, and high maintenance costs. At the opposite, electrochemical methods like ASV are cheaper, sensitive, and do not require in most cases sample pretreatment [10]-[15]. Several solid electrodes or chemically modified electrodes have been exploited in the electroanalysis of heavy metals. For the few past years, graphene materials have attracted a lot of attention due to their large theoretical surface area (2630 $\left.\mathrm{m}^{2} \cdot \mathrm{g}^{-1}\right)$ [16]; very high electrical and thermal conductivity $\left(>3000 \mathrm{~W} \cdot \mathrm{mK}^{-1}\right)$; strong mechanical strength (1 TPa) and their gas impermeability [17] [18] [19] and low production cost. Due to these excellent physical and chemical properties, graphene has become an interesting alternative for the development of electrical devices [20] and electrochemical sensors [21] [22] [23] [24]. Graphene is a single layer or few layers of graphite with $\mathrm{sp}^{2}$ carbon atoms packed in a honeycomb crystal lattice [25] [26]. It was first isolated in 2004 by Novoselov et al. [27] [28] and due to the presence of the $\mathrm{sp}^{2}$-like planes and the edge defects that are more exposed, the graphene-based electrochemical sensors present a better performance compared to glassy carbon, graphite and even carbon nanotubes sensors [29]. Within the existing techniques of graphene modified electrodes, the electrochemical reduction technique of graphene or graphene oxide on glassy carbon electrode is the most used for the fabrication of sensors [30] [31] [32]. This technique is slow and can't be used for electrodes batch production, while a more precise technique is required to obtain highly reproducible and multiple disposable sensors [33]. Nowadays, inkjet printing of functional materials becomes a very promising mask-free microfabrication technique, that allows a precise deposition of conductive organic and inorganic materials such as carbon nanotube, silver and gold [33] [34]. The materials are printed with a certain 
shape and dimension directly on a substrate [35]. Inkjet printing technology offers the advantage that, it requires absolutely no prefabrication of template as is the case with the other printing methods such as transfer printing, contact printing and aerosol printing [36] [37]. Some authors have introduced the fabrication of graphene inkjet printed electrodes and their electroanalytical applications. Dong et al. [38] reported the development of a new type of sandwich structured ionic liquid carbon nanotube graphene film (IL-CNT-GF) synthesized by a facile and effective inkjet printing method for the in situ electrochemical detection of $\mathrm{Bi}^{3+}, \mathrm{Pb}^{2+}$ and $\mathrm{Cd}^{2+}$ in environmental samples. They showed that IL and CNT modified inkjet printed electrode possesses a good sensing performance, a high sensitivity and can detect $\mathrm{Cd}^{2+}$ and $\mathrm{Pb}^{2+}$ down to $10^{-10} \mathrm{M}$. To date, stand-alone inkjet printed graphene electrodes with proper electrochemical behavior as amperometric sensors are scarce in the literature. We were therefore interested in this work in preparing and characterizing a disposable graphene inkjet printed electrode (IJPGE) as a potential analytical tool for the detection of lead and cadmium. The disposable electrode was obtained by firstly producing a series of graphene-based inkjet printed electrodes, identified as IJPGE. Secondly, an oxygen plasma treatment was applied on the active surface area of the IJPGE in order to activate the electrode surface. Finally, a bismuth solution was drop-coated on the oxygenated-IJPGE surface, followed by stabilization using electrochemical oxidation. The prepared electrodes were then successfully used for the simultaneous detection of cadmium and lead ions in acidic solution. Before their exploitation in electrochemical tests, the electrodes were characterized by Laser Scanning Microscopy (LSM), Raman spectroscopy, Scanning Electron Microscopy (SEM) coupled to Energy Dispersive X-ray (EDX), X-ray Photoelectron Spectroscopy (XPS) and Electrochemical Impedance Spectroscopy (EIS).

\section{Experimental}

\subsection{Material and Reagents}

An inkjet-printable graphene dispersion and ethyl cellulose (solid content 2.4 wt. \%) in cyclohexanone and terpineol were obtained from Sigma Aldrich (originally synthesized by the Mark Hersam group at Northwestern University, USA), while the UV curable dielectric ink EMD 6201 was purchased from SunChemical. Kapton HN(R) (polyimide PI, $125 \mu \mathrm{m}$ thickness) was obtained from Goodfellow and served as substrate. $\mathrm{Bi}\left(\mathrm{NO}_{3}\right)_{3}, \mathrm{Cd}(\mathrm{OAc})_{2}$ and $\mathrm{Pb}(\mathrm{OAc})_{2}$ were also from Sigma-Aldrich and different electrolytes of $\mathrm{HNO}_{3}, \mathrm{HCl}$ and acetate buffer (prepared from $0.2 \mathrm{M} \mathrm{CH}_{3} \mathrm{COOH}$ and $0.2 \mathrm{M} \mathrm{CH}_{3} \mathrm{COOK}$ ) were prepared with deionized water.

Two inkjet printing platforms were used in this work to fabricate the thin film graphene electrodes:

1) TheDMP-2850 material deposition printer from Fujifilm Dimatix was employed to deposit four inkjet printed layers of the graphene dispersion; 
2) The $X$-Serie Ceraprinter from Ceradrop was used to simultaneously print and photopolymerized with an integrated UV LED (FireEdge FE300 380 - 420 $\mathrm{nm}$; Phoseon Technology) the UV curable ink as insulating material in order to define accurately the electrode area and to insulate partially the graphene patterns used as electronic traces.

Disposable DimatixDMC-11610 cartridges containing 16 individually addressable nozzles and generating nominally $10 \mathrm{pL}$ droplets were used in both machines. All printing parameters, such as the voltage pulse for the piezoelectric actuation inside the nozzles, jetting frequency, droplet falling speed, overlapping distance of adjacent droplets and substrate temperature were optimized for each printed layer. After the printing of the graphene ink, the patterns were thermally cured for $1 \mathrm{~h}$ in a furnace at $400^{\circ} \mathrm{C}$. The insulation layer was deposited as a frame around the graphene pattern to create a squared working electrode area of theoretically $1 \mathrm{~mm}^{2}$ as shown in Scheme 1 .

A potentiostat ( $\mu$-Autolab, Holland) running with NOVA software was used for electrochemical measurements. A standard single compartment three-electrode cell was used with an $\mathrm{Ag} / \mathrm{AgCl} / 1 \mathrm{M} \mathrm{KCl}$ reference electrode (LEPA fabrication, Switzerland) and a coiled platinum wire electrode as counter electrode. The working electrode was an inkjet printed disposable graphene electrode. Stripping square wave voltammetry experiments for the electroanalysis of lead and cadmium were carried out without degassing the supporting electrolyte solution. A potentiostat (Palmsens, Holland) running with PS Trace software was used for the characterization of electrodes by EIS. Thus, a standard single compartment three electrodes cell was used with a commercial $\mathrm{Ag} / \mathrm{AgCl}$ reference and an inox bar as counter electrode. The working electrodes were the three different graphene-based electrodes prepared in this work. Laser Scanning Microscopy (LSM) was taken with the Keyence VK-8700 microscope. The Scanning Electron Microscopy images (SEM, FEI Teneo) were provided by a Quanta 3D FEG 200/600 equipment supplied by FEI Company. Energy Dispersive X-ray spectroscopy (EDX) was used to characterize the graphene patterns before and after the oxygen plasma treatment.

\subsection{Electrode Modification Procedure}

On a 4 layers (4L) inkjet printed graphene electrode, treated with an oxygen

\section{Active graphene surface Insulation layer Graphene layer}

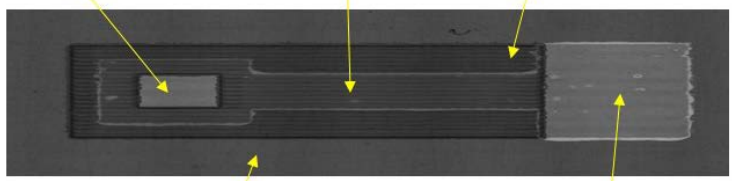

Kapton substrate

Electric contact surface

Scheme 1. A picture of the inkjet-printed disposable graphene electrode (IPGE). 
plasma (for 30 min under $0.6 \mathrm{mbar}$ ), $1 \mu \mathrm{L}$ drop of Bi (III) was deposited and dried at room temperature for few minutes. The electrode was then gently rinsed with deionized water to remove the non-adsorbed bismuth cations. Stripping square wave voltammetry in acetate buffer (at $\mathrm{pH} 4.8$ ) was performed in order to confirm the coating of bismuth on the oxygen treated electrode surface. After several scans, the electrode was removed, rinsed, dried and the stripping step was restarted in a fresh acetate buffer solution. The stabilization of the electrode was achieved and it was ready for simultaneous stripping voltammetry analysis of cadmium and lead.

\section{Results and Discussion}

\subsection{Characterization of Inkjet Graphene Electrode (GE) and Its Oxygen Treated Counterpart $\left(\mathrm{O}_{2}-\mathrm{GE}\right)$ by Raman Spectroscopy}

Figure 1 shows the Raman spectra of GE (a) and $\mathrm{O}_{2}$-GE (b). On Figure 1(a) related to the GE, numerous peaks were observed and attributed to the characteristic peak of graphene ( $\mathrm{sp}^{2}$ peak of graphite), namely $\mathrm{G}$ at $1600 \mathrm{~cm}^{-1}$. Beside this peak, D and D' signals were obtained, at $1300 \mathrm{~cm}^{-1}$ and $1610 \mathrm{~cm}^{-1}$ respectively while a $2 \mathrm{D}$ peak was noticed at $2700 \mathrm{~cm}^{-1}$. The presence of $\mathrm{D}$ and $\mathrm{D}^{\prime}$ shows that the used commercial ink contains defect or disorder [30] [31] [32]. The 2D band (also known as G' or G band) is used to determine the number of graphene layer [31] [33]: the ratio $I_{G} / I_{2 D}$ with a value of 4 indicates that 4 graphene layers are printed on the substrate. After $30 \mathrm{~min}$ of oxygen plasma treatment (Figure $1(b))$, some changes were observed: the decrease of D and D' peaks intensities due to the decrease of defects (impurities). Yet, the treatment by oxygen plasma cleaned the surface of graphene [34]. This decrease also led to a reduction of the amount of non-sp ${ }^{2}$ bonding [35] [36] [37] and to an increase of $\mathrm{sp}^{2}$ bonding (increase of graphene activated site). The increase in $\mathrm{G}$ and $2 \mathrm{D}$ peak intensity leading to a $\mathrm{I}_{\mathrm{G}} / \mathrm{I}_{2 \mathrm{D}}$ ratio of 3 indicated a reduction of the number of graphene layers

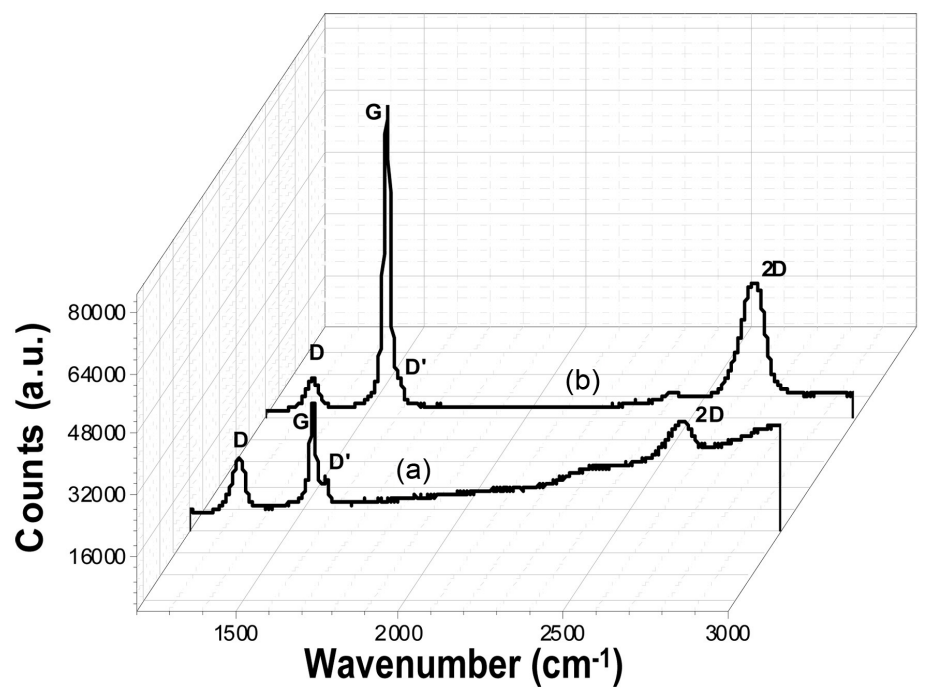

Figure 1. Raman spectra of (a) GE and (b) $\mathrm{O}_{2}$ plasma treated GE. 
from 4 (theoretically printed) to 3 after oxygen treatment; this was confirmed by the shifting of $2 \mathrm{D}$ band to lower wavenumber.

This was attributed to oxygen plasma treatment which progressively removes graphene in a layer by layer fashion [37]. Also, a decrease of the $I_{D} / I_{G}$ ratio to 0.1 indicated the reduction of defect density or disorder on the electrode surface leading to an increasing graphitic nature of graphene layers, correlated with the removal of the printed insulator [38] [39] [40]. Finally, the oxygen treatment of the electrode led to an increase of graphene activated sites on the inkjet printed surface.

\subsection{Morphologic Characterization of GE, $\mathrm{O}_{2}-\mathrm{GE}$ and $\mathrm{Bi}-\mathrm{O}_{2}-\mathrm{GE}$}

\subsubsection{Laser Scanning Microscopy (LSM)}

The LSM images of the electrodes are shown on Figure 2. Figure 2(a) presents the picture of the bare GE: one can observe that the graphene layer printed on the surface of Kapton substrate is uniform. After $\mathrm{O}_{2}$-plasma treatment (Figure 2(b)), the surface became dark due to the treatment which led to the etching and the removal of residual photoresists on this electrode surface [34]. The dark appearance of the surface is due to the high quantity of oxygen deposited on the electrode within the long oxygenation time $(30 \mathrm{~min})$ and the high plasma power used. This observation is in agreement with a previous work by Solis et al. [41]. Also, the appearance of a long strip at the center of the surface and many white points all over the electrode surface were observed. According to Zhang et al. [42], the long strip may represent the active sites (defects) density while the white points are due to pits and holes produced by the oxygen plasma treatment (this was confirmed by the SEM spectra). However, this long strip can lead to an increase in the electronic transfer on the treated oxygenated inkjet printed electrode [42]. The deposition of the bismuth (Figure 2(c)) also changes this appearance by making it become clearer. This can be due to the removal of the excess bismuth ions by washing. It was also observed that the white points present on Figure 2(b) become dark, probably due to bismuth ions that occupied different active sites.
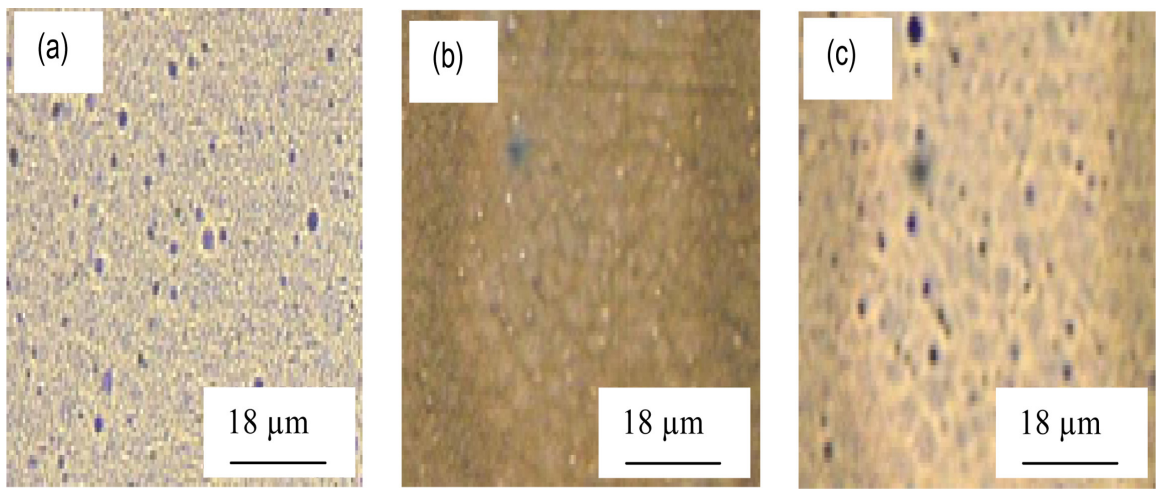

Figure 2. LSM views of (a) bare GE, (b) $30 \mathrm{~min} \mathrm{O}_{2}$ treated plasma GE and (c) $\mathrm{Bi}-\mathrm{O}_{2}$ plasma treated GE. 


\subsubsection{Scanning Electron Microscopy (SEM)}

Figure 3 represents the SEM images of GE (a), $\mathrm{O}_{2}$-plasma-GE (b) and Bi-drop$\mathrm{O}_{2}$-plasma-GE (c). From these figures, a difference of morphology was noticed. The pits and holes of Figure $3(\mathrm{~b})$ are due to the high temperature oxidative exposure (long time exposition under oxygen) [43].

This can also be explained by the oxidation of the $\pi$-network of the graphene electrode [44]. The slight morphology difference observed within the $\mathrm{O}_{2}$-plasma$\mathrm{GE}$ and the $\mathrm{Bi}-\mathrm{O}_{2}$-plasma-GE can be explained by the washing of the bismuth salt on the graphene sheet surface, leading to the production of more holes (Figure 3(c)).

\subsubsection{Energy Dispersive X-Ray Spectroscopy (EDX)}

EDX spectrum of graphene (a), $\mathrm{O}_{2}$-graphene (c) and $\mathrm{Bi}^{-} \mathrm{O}_{2}$-graphene (b) electrodes are shown on Figure 4. The peaks of carbon and oxygen with different heights are well observed on each electrode.

The observed differences in carbon peak intensities on these curves are due to the $\mathrm{O}_{2}$ plasma treatment that removes one layer of the printed graphene [34]. For oxygen peaks, the difference is attributed to the deposition of this element
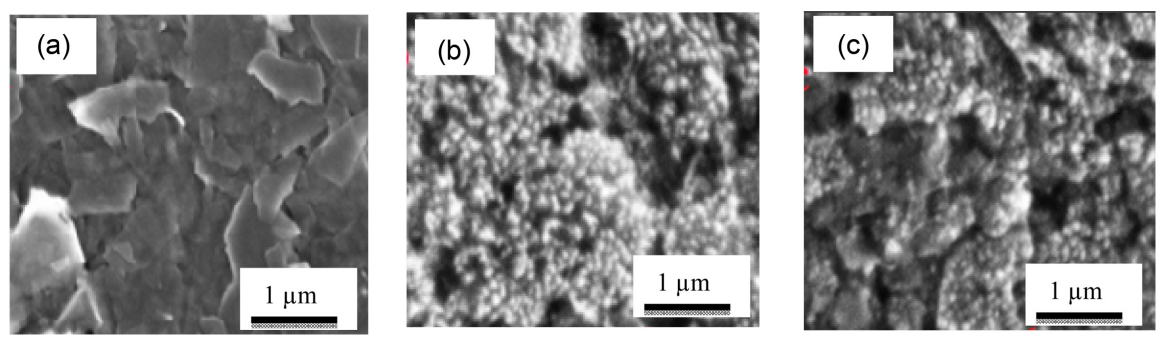

Figure 3. SEM images of high magnification $(\times 50,000)$ on (a) GE, (b) $\mathrm{O}_{2}$ plasma-GE and (c) $\mathrm{Bi}-\mathrm{O}_{2}$ plasma treated $\mathrm{GE}$.

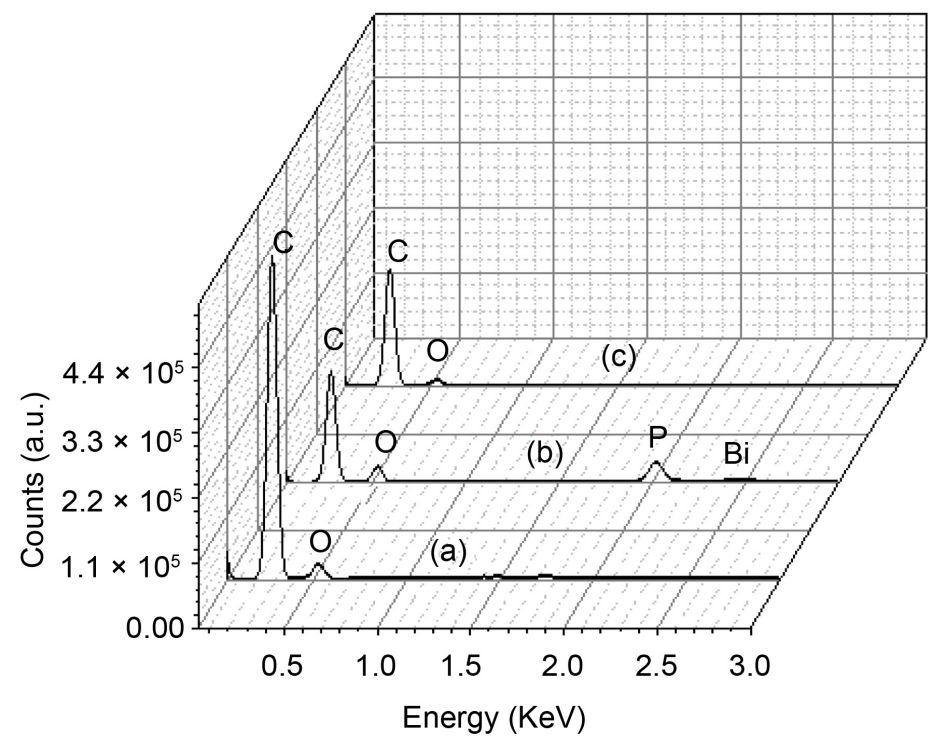

Figure 4. EDX spectra of GE (a); oxygen plasma-GE (c) and Bi-dropoxygen plasma-GE (b). 
on the surface of graphene during the treatment. The presence of bismuth on the surface of graphene electrode in Figure 4 (b) is revealed by bismuth. The phosphorus peak may arise from the ink as impurities.

\subsubsection{Electrochemical Characterization of Electrodes}

Cyclic Voltammetry analysis was used to evaluate the electron transfer properties of carbon material on various prepared electrodes in the presence of $\left[\mathrm{Fe}(\mathrm{CN})_{6}\right]^{3-}$ ions and the results are presented in Figure 5. The GE exhibited a well-defined redox peak (Figure 5(a)) in the studied potential window. The observed redox peak pair demonstrated a favorable direct electron transfer between the inkjet printed GE and the redox species. After oxygen treatment, the electrode displayed a higher signal than that registered on the GE (Figure 5(b)). This result should be due to the treatment that increased the effective surface area of the GE, thereby offering a faster electron transfer rate. After dropping 1 $\mu \mathrm{L}$ of $\mathrm{Bi} 3+$ solution on the surface of $\mathrm{O}_{2}$-plasma graphene, the peak slightly increased and shifted to more positive potentials (Figure $5(\mathrm{c})$ ).

\subsection{Preliminary Investigations on Prepared Electrodes for Heavy Metal Ions Detection}

Upon characterization, the electrodes prepared in this work were evaluated for the electrochemical detection of cadmium and lead ions by means of square wave voltammetry (SWV). The following optimized parameters (results not shown) were used: deposition time: $210 \mathrm{~s}$; deposition potential: $-1.1 \mathrm{~V}$ (vs $\mathrm{Ag} /$ $\mathrm{AgCl}$ ); electrolyte: $0.1 \mathrm{M}$ acetate buffer at $\mathrm{pH} 4.8$; frequency: $25 \mathrm{~Hz}$; amplitude: $25 \mathrm{mV}$ and potential step: $10 \mathrm{mV}$.

As shown in Figure 6, all studied electrodes displayed signals for the investigated ionic species, the bare GE being the least sensitive (curve a). However, the amperometric signal was more pronounced on $\mathrm{Bi}-\mathrm{O}_{2}$-plasma GE for $\mathrm{Pb}^{2+}$ ions

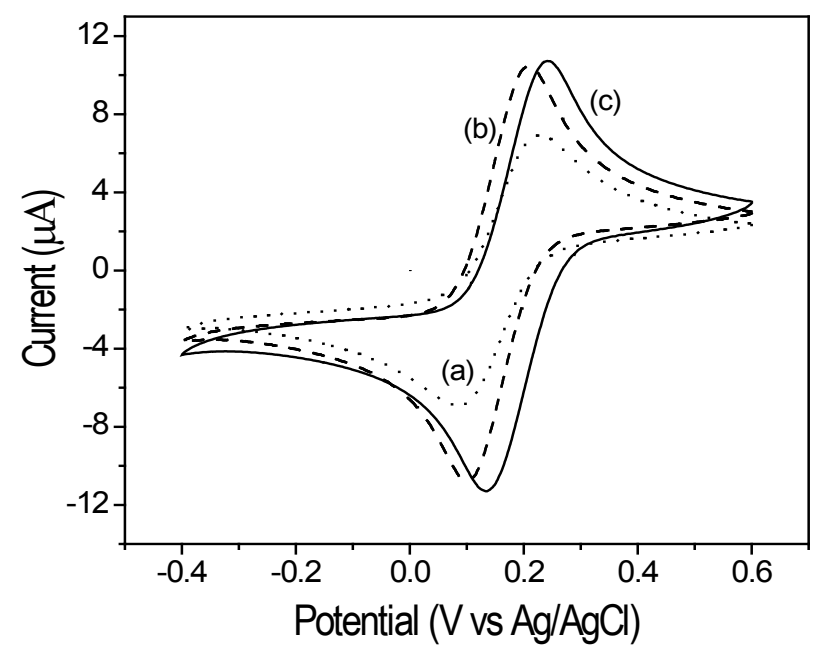

Figure 5. Cyclic voltammograms of (a) GE, (b) $\mathrm{O}_{2}$-plasma GE and (c) Bi- $\mathrm{O}_{2}$-plasma $\mathrm{GE}$ in $0.1 \mathrm{M} \mathrm{KCl}$ containing $5 \times 10^{-4} \mathrm{M}$ $\left[\mathrm{Fe}(\mathrm{CN})_{6}\right]^{3-}$ (Potential scan rate: $50 \mathrm{mV} \cdot \mathrm{s}^{-1}$ ). 


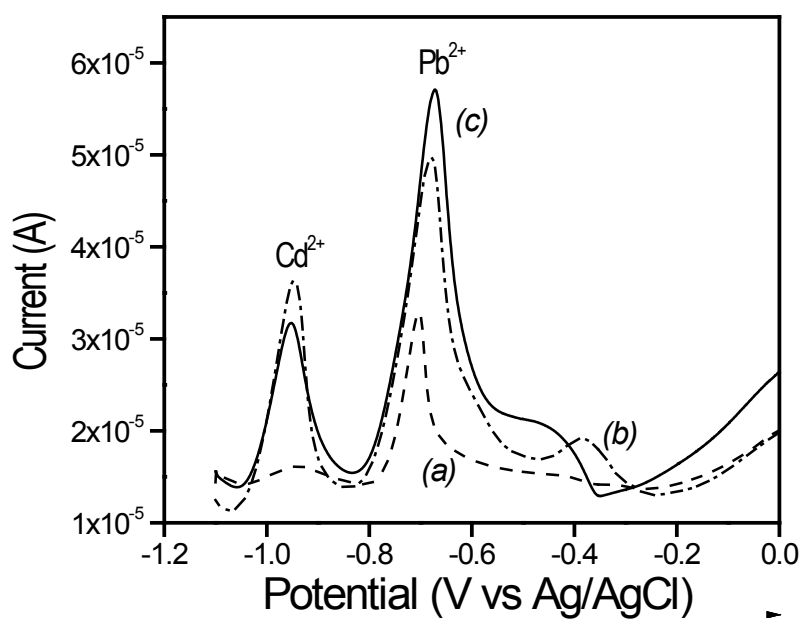

Figure 6. SWV curves obtained on (a) GE, (b) $\mathrm{O}_{2}$-plasma GE and (c) $\mathrm{Bi}-\mathrm{O}_{2}$-plasma $\mathrm{GE}$ in $0.1 \mathrm{M}$ acetate buffer at $\mathrm{pH} 4.8$ containing $0.1 \mu \mathrm{M} \mathrm{Pb}^{2+}$ and $0.1 \mu \mathrm{M} \mathrm{Cd}^{2+}$. Deposition time: 210 s; deposition potential: $-1.1 \mathrm{~V}$ (vs $\mathrm{Ag} / \mathrm{AgCl}$ ); frequency: $25 \mathrm{~Hz}$, amplitude: $25 \mathrm{mV}$, potential step: $10 \mathrm{mV}$.

(curve $\mathrm{c}$ ) although a shoulder due to the formation of $\mathrm{PbO}$ was observed around $-0.45 \mathrm{~V}$, while the tendency was reversed for $\mathrm{O}_{2}$-plasma GE (curve b) as the codeposition of $\mathrm{Bi}^{3+}$ and $\mathrm{Cd}^{2+}$ was favored.

Overall, the oxygen treatment led to an increase of the peak current of lead and cadmium, and the bismuth film contributed to increase the sensitivity of the inkjet printed graphene electrode and the formation of sharp and well-defined peaks by avoiding the formation of intermetallic instable compounds such as $\mathrm{PbO}$.

\subsection{Calibration Curves, Interference Study and Analytical Application}

In further experiments, the $\mathrm{Bi}_{-} \mathrm{O}_{2}$-plasma $\mathrm{GE}$ sensor was applied in the quantification, under optimized conditions, of $\mathrm{Cd}^{2+}$ and $\mathrm{Pb}^{2+}$ ions in a real water sample. Beforehand, the calibration curves were plotted upon variation of the concentration of both analytes in $0.1 \mathrm{M}$ acetate buffer (at $\mathrm{pH} 4.8$ ) containing varied amounts of $\mathrm{Pb}^{2+}$ and $\mathrm{Cd}^{2+}$ ions as shown in Figure 7(a). As one can observe, an increase in the sensor response was obtained when the concentration of the studied ions was varied in the range between $0.1 \mathrm{M}$ and $6 \times 10^{-8} \mathrm{M}$.

The dependence of the peak current on the concentration of these analytes (Figure $7(\mathrm{~b})$ ) followed the equations $\operatorname{Ip}(\mathrm{A})=155\left[\mathrm{Cd}^{2+}\right](\mathrm{M})-5.6 \times 10^{-7}$ and $\mathrm{Ip}(\mathrm{A})=198\left[\mathrm{~Pb}^{2+}\right](\mathrm{M})-1.38 \times 10^{-6}$, with correlation coefficients of 0.997 and 0.994 respectively. The detection limits (DL) calculated as $\mathrm{DL}=3 \mathrm{~S}_{\mathrm{b}} / \mathrm{m}$ [45] (where $\mathrm{S}_{\mathrm{b}}$ is the standard deviation of the blank and $\mathrm{m}$ the slope of the linear regression equation) were estimated to be $7.1 \times 10^{-9} \mathrm{~mol} \cdot \mathrm{L}^{-1}$ and $5.3 \times 10^{-10} \mathrm{~mol} \cdot \mathrm{L}^{-1}$ for the $\mathrm{Pb}^{2+}$ and $\mathrm{Cd}^{2+}$ ions, respectively, on the basis of signal-to-noise ratio equal to 3 . 


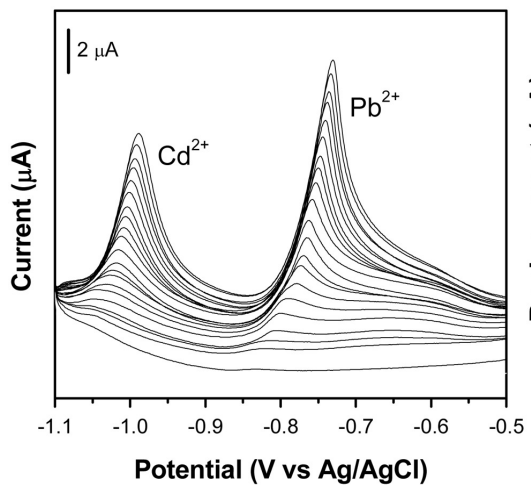

(a)

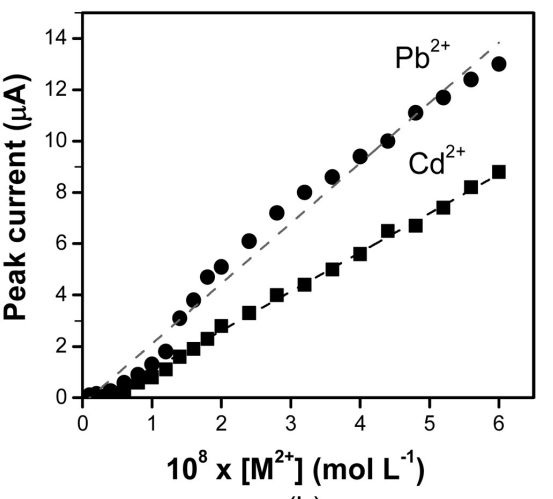

(b)

Figure 7. (a) SWV curves obtained under optimized conditions on $\mathrm{Bi}_{-} \mathrm{O}_{2}$-plasma GE in $0.1 \mathrm{M}$ acetate buffer (at $\mathrm{pH} 4.8$ ) containing varied amounts of $\mathrm{Pb}^{2+}$ and $\mathrm{Cd}^{2+}$ ions (concentrations between $0.1 \times 10^{-8} \mathrm{M}$. and $6 \times 10^{-8} \mathrm{M}$ ). (b): Calibration curves of $\mathrm{Pb}^{2+}$ and $\mathrm{Cd}^{2+}$ ions issued from Figure $7(\mathrm{a})$.

Before applying the $\mathrm{Bi}_{-} \mathrm{O}_{2}$-plasma GEsensor to a real sample analysis, its selectivity was studied by adding to the supporting electrolyte, containing $6 \times 10^{-8} \mathrm{M}$ of both $\mathrm{Cd}^{2+}$ and $\mathrm{Pb}^{2+}$ ions, the following species: $\mathrm{Zn}^{2+}, \mathrm{Fe}^{2+}, \mathrm{Cr}^{3+}, \mathrm{Ca}^{2+}, \mathrm{Cu}^{2+}$, $\mathrm{Ni}^{2+}, \mathrm{Mg}^{2+}, \mathrm{K}^{+}$and $\mathrm{Al}^{3+}$ ions. The concentration of these interfering ions was set to be 1, 10, 50 and 100-fold higher than that of $\mathrm{Cd}^{2+}$ and $\mathrm{Pb}^{2+}$ ions. For the results obtained in the last case, a real influence of added ions was noticed as shown in Figure 8.

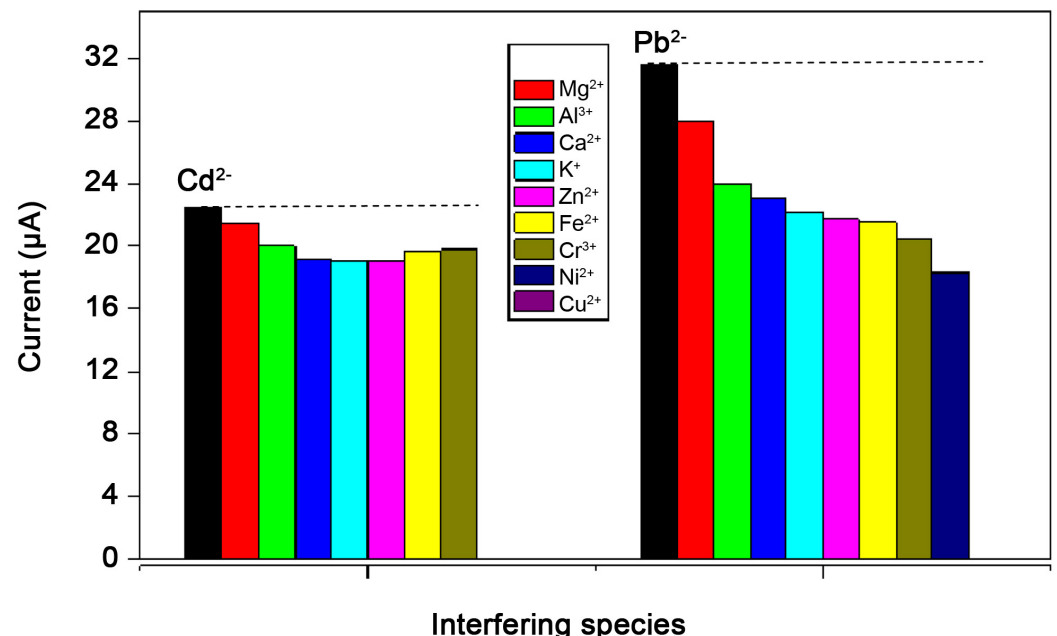

Figure 8. Variation in SWV responses of $6 \times 10^{-8} \mathrm{M} \mathrm{Pb}^{2+}$ and $6 \times 10^{-8} \mathrm{M} \mathrm{Cd}^{2+}$ upon addition of potential interfering ions, at $\mathrm{Bi}^{-\mathrm{O}_{2}}$-plasma GE in $0.1 \mathrm{M}$ acetate buffer (at $\mathrm{pH} 4.8$ ). The added concentration of interfering species over $\mathrm{Pb}^{2+}$ and $\mathrm{Cd}^{2+}$ concentration is 100 -fold.

The analysis of these results showed that the presence of $\mathrm{Zn}^{2+}, \mathrm{Fe}^{2+} \mathrm{Cr}^{3+}$ and $\mathrm{Cu}^{2+}$ ions influences the voltammetric signals of both $\mathrm{Cd}^{2+}$ and $\mathrm{Pb}^{2+}$ ions. A decrease in peak current intensities of the target ions (1.4\% to $31.5 \%)$ except in the case of $\mathrm{Cu}^{2+}$ ions where a total disappearance of $\mathrm{Cd}^{2+}$ and $\mathrm{Pb}^{2+}$ ions responses 
was observed. The effect of the interfering ions on the signal of $\mathrm{Cd}^{2+}$ and $\mathrm{Pb}^{2+}$ ions increased in the following order: $\mathrm{Zn}^{2+}<\mathrm{Fe}^{2+}<\mathrm{Cr}^{3+}<\mathrm{Cu}^{2+}$, therefore preventing the exploitation of the proposed sensor in solutions expected to contain $\mathrm{Cu}^{2+}$ ions.

Since interference was observed for low concentrations of added ions (100-fold $\mathrm{Cd}^{2+}$ or $\mathrm{Pb}^{2+}$ concentration), the proposed sensor was finally applied to detect the investigated analytes in a laboratory tap water sample. Thus, $10 \mathrm{~mL}$ of $0.1 \mathrm{M}$ acetate buffer and $10 \mathrm{~mL}$ of tap and the blank were recorded using the optimized parameters established so far in this study which showed that the sample already contained lead and cadmium. Then the solution was spiked with $8 \times 10^{-8}$ $\mathrm{mol} \cdot \mathrm{L}^{-1}$ of $\mathrm{Cd}^{2+}$ and $\mathrm{Pb}^{2+}$ ions and the recovery rate was in good agreement with the added concentration, taking into account the presence of the investigated analytes and that of $\mathrm{Cu}^{2+}$ found to be the most interfering species.

\section{Conclusion}

This work was devoted to the preparation of a disposable graphene electrode, which was obtained by printing a graphene ink on an inert Kapton substrate, followed by treatment using oxygen plasma and a bismuth salt. The electrode was characterized by various physic-chemical and electrochemical techniques, and then applied to the detection of $\mathrm{Cd}^{2+}$ and $\mathrm{Pb}^{2+}$ ions by square wave voltammetry. It was found that its sensitivity is greatly dependent on the treatment steps and on the parameters involved in the detection step by square wave voltammetry. In spite of rather high interference of some ions in the analytical application of the proposed sensor, it was shown that the analytical method developed here is simple and sensitive, and could serve as a promising tool for the monitoring of heavy metals in various polluted solutions.

\section{Acknowledgements}

LSG grateful acknowledges the support of the EPFL (Switzerland) for all facilities, as well as the Ministry of Higher Education (Cameroon) for a travel grant.

\section{Conflicts of Interest}

The authors declare that they have no competing interests.

\section{References}

[1] Samiey, B., Cheng, C.H. and Wu, J. (2014) Organic-Inorganic Hybrid Polymers as Adsorbents for Removal of Heavy Metal Ions from Solutions: A Review. Journal of Materials, 7, 673-726. https://doi.org/10.3390/ma7020673

[2] Jaishankar, M., Tseten, T., Anbalagan, N., Mathew, B.B. and Beeregowda, K.N. (2014) Toxicity, Mechanism and Health Effects of Some Heavy Metals. Interdisciplinary Toxicology, 7, 60-72. https://doi.org/10.2478/intox-2014-0009

[3] Jarup, L. (2003) Hazards of Heavy Metals Contamination. British Medical Bulletin, 68, 167-182. https://doi.org/10.1093/bmb/ldg032

[4] Lu, F. and Astruc, D. (2018) Nanomaterials for Removal of Toxic Elements from 
Water. Coordination Chemistry Review, 356, 147-164.

https://doi.org/10.1016/j.ccr.2017.11.003

[5] Fan, C.S., Liou, S.Y.H. and Hou, C.H. (2017) Capacitive Deionization of Arsenic-Contaminated Groundwater in a Single-Pass Mode. Chemosphere, 184, 924-931. https://doi.org/10.1016/j.chemosphere.2017.06.068

[6] World Health Organization (WHO) (2010). http://www.who.int/about/licensing/copyright_form/en/index.html

[7] Kaplan, I.O., Ince, M., Yonten, V. and Goksu, A. (2017) A Food Waste Utilization Study for Removing Lead (II) from Drinks. Food Chemistry, 214, 637-643.

https://doi.org/10.1016/j.foodchem.2016.07.117

[8] Gottesfeld, P. and Pokhrel, A.K. (2011) Review: Lead Exposure in Battery Manufacturing and Recycling in Developing Countries and among Children in Nearby Communities. Journal of Occupational and Environmental Hygiene, 8, 520-532. https://doi.org/10.1080/15459624.2011.601710

[9] Joseph, P. (2009) Mechanisms of Cadmium Carcinogenesis. Toxicology and Applied Pharmacology, 238, 272-279. https://doi.org/10.1016/j.taap.2009.01.011

[10] Bansod, B., Kumar, T., Thakur, R., Rana, S. and Singh, I. (2017) A Review on Various Electrochemical Techniques for Heavy Metal Ions Detection with Different Sensing Platforms. Biosensors and Bioelectronics, 94, 443-455.

https://doi.org/10.1016/j.bios.2017.03.031

[11] World Health Organization (WHO) Geneva, Switzerland (2011). http://www.who.int/about/licensing/copyright_form/en/index.html

[12] Sánchez, J., Butter, B., Rivas, B.L., Basáez, L. and Santander, P. (2015) Electrochemical Oxidation and Removal of Arsenic Using Water-Soluble Polymers. Journal of Applied Electrochemistry, 45, 151-159.

https://doi.org/10.1007/s10800-014-0785-9

[13] Abiman, P., Wildgoose, G.G., Crossley, A. and Compton, R.G. (2009) Quantitative Studies of Metal Ion Adsorption on a Chemically Modified Carbon Surface: Adsorption of Cd (II) and $\mathrm{Hg}$ (II) on Glutathione Modified Carbon. Electroanalysis, 21, 897-903. https://doi.org/10.1002/elan.200804519

[14] Abiman, P., Wildgoose, G.G., Crossley, A. and Compton, R.G. (2008) Removal of Palladium Ions from Aqueous Systems by Chemically Modified Cysteine Carbon Powder. Journal of Materials Chemistry, 18, 3948-3953. https://doi.org/10.1039/b805804k

[15] Xiao, L., Wildgoose, G.G., Crossley, A., Knight, R., Jones, J.H. and Compton, R.G. (2006) Removal of Toxic Metal-Ion Pollutants from Water by Using Chemically Modified Carbon Powders. Chemistry: An Asian Journal, 1, 614-622. https://doi.org/10.1002/asia.200600136

[16] Zhu, Y., Murali, S., Cai, W., et al. (2010) Graphene and Graphene Oxide: Synthesis, Properties and Applications. Advanced Materials, 22, 3906-3924. https://doi.org/10.1002/adma.201001068

[17] Lee, S., Bong, S., Ha, J., Kwak, M., Park, S.-K. and Piao, Y. (2015) Electrochemical Deposition of Bismuth on Activated Graphene-Nafion Composite for Anodic Stripping Voltammetric Determination of Trace Heavy Metals. Sensors and Actuators B, 215, 62-69. https://doi.org/10.1016/j.snb.2015.03.032

[18] Ke, Q. and Wang, J. (2016) Graphene-Based Materials for Supercapacitor Electrodes: A Review. Journal Materiomics, 2, 37-54.

https://doi.org/10.1016/j.jmat.2016.01.001 
[19] Tan, L.L., Chai, S.P. and Mohamed, A.R. (2012) Synthesis and Applications of Graphene-Based $\mathrm{TiO}_{2}$ Photocatalysts. Chemistry and Sustainability Chemistry, 5, 1868-1882. https://doi.org/10.1002/cssc.201200480

[20] Novoselav, K.S., Fal'ko, V.I., Colombo, L., Gellert, P.R., Schwab, M.G. and Kim, K. (2012) A Roadmap for Graphene. Nature, 190, 192-200. https://doi.org/10.1038/nature11458

[21] Ratinac, K.R., Yang, W., Gooding, J.J., Thordarson, P. and Braet, F. (2011) Graphene and Related Materials in Electrochemical Sensing. Electroanalysis, 23, 803-826. https://doi.org/10.1002/elan.201000545

[22] Yang, W., Ratinac, K.R., Ringer, S.P., Thordarson, P., Gooding, J.J. and Braet, F. (2010) Carbon Nanomaterials in Biosensors: Should You Use Nanotube or Graphene? Angewandte Chemie International Edition, 49, 2114-2138. https://doi.org/10.1002/anie.200903463

[23] Shan, C., Yang, H., Song, J., Han, D., Ivaska, A. and Niu, L. (2009) Direct Electrochemistry of Glucose Oxidase and Biosensing for Glucose Based on Graphene. Analytical Chemistry, 81, 2378-2382. https://doi.org/10.1021/ac802193c

[24] Kuila, T., Bose, S., Khanra, P., Mishra, A.K., Kim, N.H. and Lee, J.H. (2011) Recent Advances in Graphene-Based Biosensors. Biosensors and Bioelectronics, 26, 4637-4648. https://doi.org/10.1016/j.bios.2011.05.039

[25] Liu, Y., Dong, X. and Chen, P. (2012) Biological and Chemical Sensors Based on Graphene Materials. Chemical Society Reviews, 41, 2283-2307.

https://doi.org/10.1039/C1CS15270J

[26] Choi, W., Lahiri, I., Seelaboyina, R. and Kang, Y.S. (2010) Synthesis of Graphene and Its Applications: A Review. Critical Reviews in Solid State and Material Science, 35, 52-71. https://doi.org/10.1080/10408430903505036

[27] Winnik, J. (2012) Searching for Structural Shifts in Science: Graphene R and D before and after Novoselov et al. (2004). Proceedings of the 17 th International Conference on Science and Technology Indicators, Montréal, 1-12. https://www.researchgate.net/publication/263580864

[28] Novoselov, K.S., Geim, A.K., Morozov, S.V., Jiang, D., Zhang, Y., Dubonos, S.V., Grigorieva, I.V. and Firsov, A.A. (2004) Electric Field Effect in Atomically Thin Carbon Films. Science, 306, 666-669. https://doi.org/10.1126/science.1102896

[29] Banhart, F., Kotakoski, J. and Krasheninnikov, A.V. (2011) Structural Defects in Graphene. American Chemical Society Nano, 5, 26-41. https://doi.org/10.1021/nn102598m

[30] Devadas, B., Rajkumar, M., Chen, S.M. and Saraswathi, R. (2012) Electrochemically Reduced Graphene Oxide, Neodymium Hexacyanoferrate Modified Electrode for the Electrochemical Detection of Paracetamol. International Journal of Electrochemical Science, 7, 3339-3349. http://www.electrochemsci.org

[31] Zhang, Y., Zhang, M., Wei, Q., Gao, Y., Guo, L., Al-Ghanim, K.A., Mahboob, S. and Zhang, X. (2016) An Easily Fabricated Electrochemical Sensor Based on a Graphene Modified Glassy Carbon Electrode for Determination of Octopamine and Tyramine. Sensors, 16, 535-548. https://doi.org/10.3390/s16040535

[32] Jian, J.M., Liu, Y.Y., Zhang, Y.L., Guo, X.S. and Cai, Q. (2013) Fast and Sensitive Detection of $\mathrm{Pb}^{2+}$ in Foods Using Disposable Screen-Printed Electrode Modified by Reduced Graphene Oxide. Sensors, 13, 13063-13075. https://doi.org/10.3390/s131013063

[33] Lesch, A., Cortes-Salazar, F., Prudent, M., Delobel, J., Rastgar, S., Lion, N., Tissot, J.D., Tacchini, P. and Girault, H. (2014) Large Scale Inkjet-Printing of Carbon 
Nanotubes Electrodes for Antioxidant Assays in Blood Bags. Journal of Electroanalytical Chemistry, 717-718, 61-68. https://doi.org/10.1016/j.jelechem.2013.12.027

[34] Singh, M., Haverinen, H.M., Dhagat, P. and Jabbour, G.E. (2010) Inkjet Printing-Process and Its Applications. Advanced Materials, 22, 673-685. https://doi.org/10.1002/adma.200901141

[35] Alves, A.P., Martins, J., Da Silva, H.P., Lourence, A., Fred, A. and Ferreira, H. (2014) Experimental Study and Evaluation of Paper-Based Inkjet Electrodes for ECG Signal Acquisition. Proceedings of the International Conference on Physiological Computing Systems, Vol. 1, 275-281.

https://doi.org/10.5220/0004720802750281

[36] Lawes, S., Riese, A., Sun, Q., Cheng, N. and Sun, X. (2015) Printing Nanostructured Carbon for Energy Storage and Conversion Applications. Carbon, 92 150-176. https://doi.org/10.1016/j.carbon.2015.04.008

[37] Tortorich, R.P. and Choi, J.W. (2013) Inkjet Printing of Carbon Nanotubes. Nanomaterials, 3, 453-468. https://doi.org/10.3390/nano3030453

[38] Dong, S., Wang, Z., Asif, M., Wang, H., Yu, Y., Hu, Y., Liu, H. and Xiao, F. (2017) Inkjet Printing Synthesis of Sandwich Structure Ionic Liquid Carbon Nanotube-Graphene Film: Toward Disposable Electrode for Sensitive Heavy Metal Detection in Environmental Water Sample. Industrial and Engineering Chemistry, 56, 1696-1703. https://doi.org/10.1021/acs.iecr.6b04251

[39] Ardavan, Z., Gwan, H.L., Sung, J.A., Sunwoo, L., Nithin, M., Mauricio, T., Takuya, H., Catalin, R.P., James, H. and Nikhil, K. (2014) Effect of Defects on the Intrinsic Strength and Stiffness of Graphene. Nature Communication, 5, 3186. https://doi.org/10.1038/ncomms4186

[40] Yang, D.X., et al. (2009) Chemical Analysis of Graphene Oxide Film after Heat and Chemical Treatment by X-Ray Photoelectrons and Micro-Raman Spectroscopy. Carbon, 47, 145-152. https://doi.org/10.1016/j.carbon.2008.09.045

[41] Solis, F.P., Paredes, J.I., Villar-Rodil, S., Guardia, L., Fernandez-Merino, M.J., Dobrik, G., Biro, L.L.P., Martinez, A. and Tascon, J.M.D. (2011) Global and Local Oxidation Behavior of Reduced Graphene Oxide. Journal of Physical Chemistry C, 115, 7956-7966. https://doi.org/10.1021/jp2003744

[42] Zhang, G.H., et al. (2015) Electrochemistry at Highly Oriented Pyrolytic Graphite (HOPG): Lower Limit for the Kinetics of Outer-Sphere Redox Process and General Implications for Electron Transfer Models. Physical Chemistry Chemical Physics, 17, 11827-11838. https://doi.org/10.1039/C5CP00383K

[43] Nie, Z.H., Wang, H.M., Ma, Y., Kasim, J., Wu, Y.H. and Shen, Z.X. (2008) Tunable Stress and Controlled Thickness Modification in Graphene by Annealing. ACS Nano, 2, 1033-1039. https://doi.org/10.1021/nn800031m

[44] Gokus, T., Nair, R.R., Bonetti, A., Böhmler, M., Lombardo, A., Novoselav, K.S., Geim, A.K., Ferrari, A.C. and Hartschuh, A. (2009) Making Graphene Luminescent by Oxygen Plasma Treatment. ACS Nano, 3, 3963-3968. https://doi.org/10.1021/nn9012753

[45] Ghoneim, M.M., Hassanein, A.M., Hammam, E. and Beltagi, A.M. (2000) Simultaneous Determination of $\mathrm{Cd}, \mathrm{Pb}, \mathrm{Cu}, \mathrm{Sb}, \mathrm{Bi}, \mathrm{Se}, \mathrm{Zn}, \mathrm{Mn}, \mathrm{Ni}, \mathrm{Co}$ and $\mathrm{Fe}$ in Water by Differential Pulse Stripping Voltammetry at a Hanging Mercury Drop Electrode. Fresenius Journal of Analytical Chemistry, 367, 378-383. https://doi.org/10.1007/s002160000410 